\title{
Obesity and dentistry: a growing problem
}

\author{
D. Reilly, ${ }^{1}$ C. A. Boyle ${ }^{2}$ and D. C. Craig ${ }^{3}$ \\ VERIFIABLE CPD PAPER
}

- Reviews obesity and its consequences from a dental perspective.

- Highlights specific challenges, in particular in relation to conscious sedation, that may exist when treating obese patients and the lack of evidence based guidance in the literature.

- Makes practical recommendations for managing obese patients who require dental care.

\begin{abstract}
Obesity has increased at an alarming rate in recent years. It is now a worldwide public health problem. The World Health Organisation (WHO) classifies obesity as a chronic disease. Affected individuals are at increased risk of hypertension, heart disease and other illnesses. There are also important social implications.

Within dentistry and particularly in the provision of conscious sedation, obesity can be a potential complicating factor. For example, the position of anatomical landmarks may be less obvious if surrounded by fatty tissue. Very obese patients may be housebound or have difficulty accessing dental surgeries. Dental chairs may not be of an appropriate design to accommodate some obese patients. However, little information or advice on this topic is available in the literature.

This article reviews obesity from a dental perspective. Challenges in providing dental care for obese patients are identified and practical recommendations made for their management.
\end{abstract}

\section{Introduction}

The World Health Organisation (WHO) defines obesity as 'Abnormal or excessive fat accumulation that may impair health.' ${ }^{1}$ Definitions of what is considered overweight vary with time and from country to country. The current definition of overweight proposed by the WHO and the US National Institutes of Health is a BMI (Body Mass Index) of $25 \mathrm{~kg} / \mathrm{m}^{2}$ or more. ${ }^{2}$ Individuals are classified as obese rather than overweight when BMI is $30 \mathrm{~kg} / \mathrm{m}^{2}$ or more.

In 1995 an expert panel associated with the National Institutes of Health (NIH) convened to assess the association between weight levels and disease risk. The panel reviewed data from approximately 394 studies, publishing its findings in Clinical Guidelines on the Identification, Evaluation and Treatment of Overweight and Obesity

\footnotetext{
${ }^{1}$ Senior Dental Officer, Tower Hamlets Primary Care Trust, Barkantine Dental Clinic, 121 Westferry Road, London, E14 8JH; ${ }^{2 * 3}$ Consultants in Special Care Dentistry, Department of Sedation and Special Care Dentistry, Kings College London Dental Institute at Guy's, Kings College and St Thomas' Hospitals, Floor 26, Tower Wing Great Maze Pond, London, SE1 9RT

*Correspondence to: Dr Carole Boyle

Email: carole.boyle@kcl.ac.uk
}

\section{Refereed Pape}

Accepted 10 July 2009

DOI: 10.1038/sj.bdj.2009.717

${ }^{\oplus}$ British Dental Journal 2009; 207: 171-175 in 1998. ${ }^{2}$ Use of Body Mass Index (BMI) to classify obesity was recommended and the WHO adopted this classification. BMI is defined as the weight in kilograms divided by the square of the height in metres $(\mathrm{kg} /$ $\mathrm{m}^{2}$ ). International classifications of adult underweight, overweight and obesity according to BMI are shown in Table 1.

BMI is a clinically useful measure of being overweight and obesity for both male and female adults. It is easy to calculate and is considered more appropriate than simple weighing. However, the concept of BMI has significant limitations. It ignores many factors such as differences in muscle mass, bone mass and genetic make up. Thus, BMI alone may not be an entirely appropriate measure of overweight or obesity. For example, BMI may overestimate adiposity among persons who are very athletic and have a large muscle mass. ${ }^{3}$ Underestimation can occur in individuals who have lost muscle mass such as the ill or elderly.

The WHO Child Growth Standards, launched in April 20064 include BMI charts for infants and young children up to the age of five. For children aged five to 14 years, there is no standard definition of obesity applied worldwide and measuring obesity proves challenging. The WHO is currently developing an international

\begin{tabular}{l|l}
\hline \multicolumn{2}{l}{ Table 1 Body Mass Index classification } \\
\hline CLASSIFICATION & BMI \\
\hline Underweight & $<18.5$ \\
\hline Healthy weight & $18.5-24.9$ \\
\hline Overweight & $25.0-29.9$ \\
\hline Obesity class I & $30.0-34.9$ \\
\hline Obesity class II & $35.0-39.9$ \\
\hline Obesity class III & $40+$ \\
\hline
\end{tabular}

growth reference for school age and adolescent children.

Despite the inherent problems, BMI is still the most common classification used when discussing obesity. Other methods of measuring obesity include the use of skin fold callipers, bioelectrical impedance analysis, dual energy X-ray asorptiometry and hydrostatic weighing. These methods vary in reliability but most require expensive equipment and staff training.

Recent evidence has indicated that waist circumference or waist-to-hip ratio measurements may be a better disease risk predictor than BMI. ${ }^{5}$ Research in this area is ongoing but current NICE obesity guidelines advise using waist circumference as well as BMI to help assess disease risk in patients with a BMI less than 
35. ${ }^{6}$ Assessment of the health risks associated with being overweight and obesity in adults should be based on both BMI and waist circumference as shown in Table 2.

\section{Prevalence of obesity}

Adult (aged 16 or over) obesity in England has risen from 13\% for men and 16\% for women in 1993 to 24\% for both men and women in 2007. Prevalence of obesity in childhood also increased between 1995 and 2007, from $11 \%$ in 1995 to $17 \%$ in 2007 among boys and from $12 \%$ in 1995 to $16 \%$ in 2007 among girls. Obesity rates are also increasing in Europe and in other "westernised' and less developed countries. ${ }^{7}$

Incidence of obesity is particularly high in the United States: according to the Center for Disease Control, in 2005-2006, $33.3 \%$ of men and 35.3\% of women were obese (BMI more than $30 \mathrm{~kg} / \mathrm{m}^{2}$ ). ${ }^{8}$ Obesity in children and adolescents aged 2-9 for the years 2003-2006 was $16.3 \%$. $^{9}$

\section{Causes of obesity}

Why some people remain lean while others become obese is controversial. Explanations may be generalised into two, essentially polar views.

One view suggests obesity results from a fundamental lack of discipline on the part of the affected individual. The alternative view suggests that body fat composition is physiologically controlled and that any deviation from the baseline triggers a potent homeostatic response to resist that change. In recent years the latter hypothesis has received experimental support. ${ }^{10}$ A number of genes have also been identified that contribute to animal and human obesity, ${ }_{11}^{11}$ so the evidence that obesity is not simply a personal failing is persuasive.

\section{Consequences of obesity}

Each year obesity costs the UK economy $£ 3.5$ billion, results in 30,000 deaths and 18 million working days lost through sickness. ${ }^{12}$

The WHO's World Health Report 2002 ${ }^{13}$ estimates that over $7 \%$ of all disease burden in developed countries is caused by a raised BMI. WHO concluded that around a third of coronary heart disease and ischaemic stroke, and almost 60\% of hypertensive disease in developed countries is associated with a BMI in excess of 25.

Table 2 BMI, waist circumference and disease risk

\begin{tabular}{l|l|l|l|}
\hline BMI classification & \multicolumn{2}{|l|}{ Waist circumference } & Very high \\
\hline Overweight & Low & High & High risk \\
\hline Obesity I & No increased risk & Increased risk & \\
\hline $\begin{array}{l}\text { For men, waist circumference of less than } 94 \mathrm{~cm} \text { is low, } 94-102 \mathrm{~cm} \text { is high and more than } 102 \mathrm{~cm} \text { is very high. } \\
\text { For women, waist circumference of less than } 80 \mathrm{~cm} \text { is low, } 80-88 \mathrm{~cm} \text { is high and more than } 88 \mathrm{~cm} \text { is very high. }\end{array}$ \\
\hline
\end{tabular}

\section{Definition of bariatrics}

Bariatrics is the branch of medicine that deals with the causes, prevention and treatment of obesity. ${ }^{14}$ The term 'bariatric' is widely used throughout the literature referring to obese patients. 'Bariatric dentistry' does not yet appear to be a term used in the literature but may be an appropriate way of referring to dentistry for this group of patients.

\section{Physiological effects}

Increasing body adiposity is accompanied by profound changes in physiological function. These changes vary depending on the distribution pattern of body fat. Generalised obesity alters the total blood volume and cardiac function, whereas the distribution of fat around the thoracic cage and abdomen restricts respiratory function. Intra-abdominal fat deposits are a major contributor to the development of hypertension, elevated plasma insulin concentrations, insulin resistance, diabetes mellitus and hyperlipidaemia. ${ }^{15}$

\section{Immune function}

Obese individuals may have a higher incidence of infection and delayed wound healing. Obesity impairs the cell-mediated immune responses and decreases lymphocyte immune function and natural killer T-cell activity.$^{16}$

Leptin, a hormone produced by adipocytes, stimulates pro-inflammatory responses. ${ }^{17}$ Hyperleptinaemia is common in most obese individuals and causes generalised sympathetic activation, stimulation of vascular inflammation and oxidative stress. These contribute to the pathogenesis of hypertension, atherosclerosis and left ventricular hypertrophy. ${ }^{18}$

\section{Haematological function}

Platelet hyperactivity is associated with increased von Willebrand factor in obesity.
Obese patients also have increased fibrinogen, factor VII and factor VIII. ${ }^{19}$ Thus, a hypercoagulable state exists alongside obesity. In addition, obese individuals have increased levels of plasminogen activator inhibitor-1 resulting in a state of hypofibrinolysis. The net result of these haemostatic and fibrinolytic disturbances is that obese patients are at elevated risk of developing cardiovascular disease. ${ }^{20}$

\section{Specific medical conditions associated with obesity}

\section{Hypertension}

Hypertension is the most common obesityrelated disease. For each $10 \mathrm{~kg}$ in weight, systolic arterial blood pressure increases by $3-5 \mathrm{mmHg}$ and diastolic pressure by 2 mmHg. ${ }^{21}$

\section{Cardiovascular disease}

Cardiovascular disease is already the world's number one cause of death. For each unit increase in BMI, the risk of heart failure increases by $5 \%$ for men and 7\% for women. ${ }^{22}$

\section{Diabetes mellitus}

Diabetes has rapidly become a global epidemic with the WHO projecting that deaths resulting from this disease will increase by $50 \%$ worldwide in the next ten years. ${ }^{23}$ Prospective population studies confirm a close association between increasing body fatness and type II diabetes. ${ }^{24}$

\section{Sleep breathing disorder}

Large amounts of fat in the chest and abdomen may compromise respiratory function. This is exaggerated when an obese subject lies flat. Sleep breathing disorder is common among obese individuals. In the Swedish Obese Subjects Study which examined 3,034 subjects with BMI above 35, over 50\% of 
men and one third of women reported snoring and apnoea. ${ }^{21}$ As a comparison, only $15.5 \%$ of Swedish men of comparable age were self-reported snorers.

Several groups have reported an increased risk of myocardial infarction and stroke in sleep apnoea. Snoring is a strong risk factor for sleep-related strokes, and symptoms of sleep apnoea increase the risk of cerebral infarction. ${ }^{25}$

\section{Cancer}

Large prospective studies indicate a causal link between obesity and cancer of the colon, endometrium, kidney and oesophagus. ${ }^{26}$ This suggests that overeating may be the largest avoidable cause of cancer in non-smokers. ${ }^{26}$

\section{Fatty liver disease}

Excessive fat accumulation in the liver can lead to liver cirrhosis as the capacity of the liver to safely store potentially hepatotoxic fatty acids is overwhelmed. ${ }^{27}$

\section{Gallbladder disease}

Due to higher cholesterol levels in the gall bladder, overweight and obese individuals are more likely to develop gallstones. ${ }^{28}$

\section{Gastro-Oesophageal}

Reflux Disease (GORD)

Obesity may cause the communication between the lower oesophageal sphincter and the stomach to become impaired. Consequently, stomach contents can reflux into the oesophagus. ${ }^{29}$

\section{Osteoarthritis}

Extra weight puts additional load on joints. The cartilage that cushions the joints can wear prematurely, causing pain and stiffness. The lower back, knees and hips are particularly affected. The risk of knee arthritis, for example, increases by 35\% for every $5 \mathrm{~kg}$ in weight gain. ${ }^{30}$

\section{Reproductive problems}

Women who are overweight may have irregular menstrual periods and difficulties conceiving. ${ }^{31}$ Impotence may also be linked to obesity. ${ }^{32}$

\section{Treatment of obesity}

Established obesity is difficult to treat. Approaches include dietary therapy, increasing physical activity and cognitive behavioural therapy. Pharmacotherapy is also an important method of treatment for some obese patients.

Drugs which promote weight loss should only be used as part of a comprehensive treatment program in selected patients because of concerns about their adverse effects and long-term safety. Two categories of drugs may be used: appetite suppressants and drugs that decrease absorption. $^{2}$

Surgical procedures such as gastric banding or gastric bypass can offer an effective treatment for obesity. However, reducing the capacity of the stomach in this manner is associated with increased levels of acid in the oral cavity. This directly contributes to caries and tooth erosion..$^{33}$

\section{Implications of obesity for dentistry}

Dentistry for obese patients can pose challenges: some of these are well-documented such as the increased likelihood of periodontal disease in obese patients. ${ }^{34}$ Other potential complications, including those associated with conscious sedation, are less well described. Specific examples of the possible implications of obesity for patients and the dental team that care for them are considered below.

\section{Physical environment}

Obese patients must be able to access dental treatment centres. Barriers to care may include difficult access from a car park, narrow doorways or corridors and cramped toilet facilities. In the waiting room obese patients may be concerned where they can safely sit. Chairs of predefined 'normal' dimensions will often not accommodate moderate or severely obese patients: armless chairs are less restrictive.

\section{Dental chair}

Enquiries made to a number of manufacturers of dental chairs, suggest that the maximum lifting weight for modern chairs is approximately $140 \mathrm{~kg}$ (23 stones). This is considerably lower than the weight of many obese patients.

\section{Alternatives to the conventional dental chair}

One option is to refer the patient to the hospital environment where the patient may be treated on an operating table or trolley. Another possible solution for obese patients is a custom-made chair such as the DIACO $^{35}$ dental chair. Although originally designed for treating wheelchair users, the manufacturers also promote the chair as suitable for obese patients. Unlike conventional dental chairs which change position by electric motors, the DIACO mechanism is hydraulic. It has a safe working load of $500 \mathrm{~kg}$ (79 stones). However, the retail cost of this chair (approximately £30,000) largely prohibits its use outside a specialist and well-funded treatment centre.

\section{Weighing scales}

Height and weight measurements may be important for a dentist considering providing treatment for obese patients. Weighing scales should have a wide base to allow the patient to securely balance, a nearby handle rail for support and a high maximum limit. The scales should be located in a non-public area away from the gaze of other patients, staff and anyone accompanying the patient.

\section{Blood pressure cuffs}

Large adult blood pressure cuffs should be available. Using a cuff that is too small will overestimate the systemic arterial blood pressure. To avoid errors, bladder width should be $40-50 \%$ of the upper arm circumference. ${ }^{36}$

\section{Legal perspective}

Advice was sought from dental indemnity companies on managing patients who exceed the documented maximum lifting weight of a conventional dental chair. These organisations advised against the use of a conventional dental chair to treat such patients. It was acknowledged that if patients are refused treatment because of their weight, they might be able to invoke the Disability Discrimination Act (2005) and make a formal complaint. This complaint may be valid on the basis of discrimination through no fault of the patient. It was advised that a formal complaint should be accepted and managed appropriately. However, the action of the clinician in refusing a patient treatment, based on the safe weight limit of the dental chair, would be upheld as justified.

\section{Managing medical emergencies}

It has been demonstrated that obese patients frequently report shortness of breath and 
chest discomfort. While this is in part due to alteration in respiratory mechanics and lung volumes, it is important to be aware that an acute medical condition may be present such as atypical angina, myocardial infarction, or pulmonary embolism.

Difficulty or inability to establish intravenous access has been well-documented in the obese population. ${ }^{37}$ Airway management for obese patients is also potentially more complicated than for the non-obese. ${ }^{38}$ 'Intramuscular' injections in an obese patient's thigh or buttock are more likely to be into fat, which has a relatively poor blood supply, leading to unpredictable therapeutic effects. Also, dosages for many drugs are weight-based. Standard doses of emergency drugs, based on pharmacokinetics obtained in people of average weight, may not be appropriate for obese patients. ${ }^{39}$ Considering these factors, obese patients are at potentially greater risk in the event of a medical emergency.

\section{Practical considerations}

It can be diffıcult carrying out dental care for an obese patient: the landmarks for placement of an inferior alveolar nerve block can be impossible to palpate through excess soft tissue. It may be impossible to palpate cervical lymph nodes in a large neck. Soft tissues can also make retraction with a normal sized mirror unsafe: a 'lax' tongue retractor can be useful.

\section{Conscious sedation}

When thinking about conscious sedation for obese patients the potential difficulties in airway management and intravenous cannulation should be considered. The provision of inhalation sedation with nitrous oxide during which oxygen levels are maintained at or above 30\% may be more appropriate. If intravenous sedation with midazolam is proposed, the overall benefit to the patient must be carefully weighed up against the increased likelihood of significant respiratory depression and the difficulties in managing a respiratory complication.

\section{Manual handling}

Despite a projection that almost one third of the UK population is likely to be obese (BMI > greater than or equal to 30) by 2010, $40-70 \%$ of NHS Trusts did not have a bariatric policy in place in 2007.40 Among ambulance service staff that had received manual handling training, 64.7\% reported no additional training relating to bariatric patients. These findings have prompted recommendations from the Health and Safety Executive that strategic policies need to be put in place for the rapidly growing obese population in England. These policies should address not only manual handling but also building design, equipment and training needs. Dental staff, particularly those who may treat obese patients on a domiciliary basis, also require specific training to avoid injury to themselves.

\section{Practical recommendations}

Obesity is a multifaceted subject. It has many causes and many health and practical implications, which must be factored into dental treatment planning.

\section{Before the patient enters the surgery}

Practice staff should be sensitive to the needs of obese patients. Potential difficulties with access, stairs, mobility and seating should be identified and appropriate assistance offered. Armless waiting room chairs should be available. Suitable weighing scales and a height scale to calculate BMI ought to be available as well as an appropriately sized blood pressure cuff.

\section{In the surgery}

BMI should be calculated as this provides some indication of the likely level of disease risk and airway management risk. However, be aware of the limitations of BMI. It is a useful guide but should be used in combination with other information about the patient to determine an appropriate treatment plan. Know the safe working limit of the dental chair and be prepared to refer patients elsewhere if this limit is exceeded.

Ask targeted medical history questions. Obese patients are more likely to have additional health problems, which must be explored. In addition to a full medical history, ask questions which may highlight problems with airway management:

- Are you aware of a snoring habit when asleep?

- Do you regularly wake up during the course of a night's sleep?

- Do you often feel tired during the day?

Positive responses suggest the possibility of obstructive sleep apnoea.
Check arterial blood pressure. Be aware that hypertension is the most common obesity-related disease and may be undiagnosed. If diastolic pressure is over 100 $\mathrm{mmHg}$, referral to the patient's general medical practitioner may be appropriate for investigation to reduce the risk of cerebrovascular accident.

Give diet advice on the consumption of high calorie foods and drinks which are a major contributor to obesity and dental decay. Although evidence for a direct association between dental caries and obesity is limited ${ }^{41}$ a dental professional is suitably qualified to offer basic nutritional advice.

\section{Conclusions}

Being overweight increases the likelihood of a patient having associated health and social problems, which may affect access to dental services and dental management. There is a widespread lack of knowledge or protocols for managing the clinical and practical implications of obesity.

Potentially, litigation may act as a catalyst for changing practice. Bariatric policies, supported by an appropriate evidence-base, need to be put in place to reduce the likelihood of patient complaints and unsafe clinical practice.

1. World Health Organisation, 2006. Obesity and overweight [online] Available at www.who.int/mediacentre/factsheets/fs311/en/index.html Accessed 19 February 2008.

2. National Institutes of Health. Clinical Guidelines on the Identification, Evaluation, and Treatment of Overweight and Obesity in Adults: The Evidence Report. NIH publication No 98-4083, Washington DC: National Heart Lung and Blood Institute in cooperation with the National Institute of Diabetes and Digestive Kidney Diseases, September 1998.

3. The Asia-Pacific Perspective: Redefining Obesity and its Treatment. Sydney: Health Communications Australia Pty Ltd, 2000.

4. Onis M. WHO Child Growth Standards based on length/height, weight and age. Acta Paediatrica 2006; 95 (Suppl 450): 76-85.

5. Yuuf $S$, Hawken $S$, Ounpuu L et al. Obesity and the risk of myocardial infarction in 27,000 participants from 52 countries: a case control study. Lancet 2005; 366: 1640-1649.

6. National Institute for Health and Clinical Excellence Obesity. Guidance on the prevention, identification assessment and management of overweight and obesity in adults and children, December 2006

7. Health Profile of England Report, Department of Health 2008; 27 January 2009.

8. Ogden C L, Carroll M D, McDowell M A, Flegal K M Obesity among adults in the United States - no change since 2003-2004. NCHS data brief no 1. Hyattsville, MD: National Center for Health Statistics, 2007.

9. Ogden C L, Carroll M D, Flegal K M. High Body Mass Index for age among US children and adolescents, 2003-2006. JAMA 2008; 299: 2401-2405.

10. Friedman J M. A war on obesity, not the obese. Science 2003; 299: 856-858.

11. O'Rahilly S, Faroogi I S, Yeo G et al. Minireview: Human obesity-lessons from monogenic disorders. 
Endocrinology 2003; 144: 3757-3764.

12. Haslam D, Sattar N, Lean M, Obesity - time to wake up. BMJ 2006; 333: 641.

13. World Heatlh Organisation 2002, World Health Report [online] www.who.int/whr/2002/en Accessed 13 March 2009

14. 'Bariatrics'. In: The American heritage dictionary of the English language, 4th ed. Houghton, 2000. Retrieved 14 February 2006

15. Taira K, Hikita M, Kobayashi J et al. Delayed post-prandial lipid metabolism in subjects with intra-abdominal visceral fat accumulation. Eur J Clin Invest 1999; 29: 301-308

16. Kelley D S, Daudu P A. Fat intake and immune response. Prog Food Nutr Sci 1993; 17: 41-63.

17. Lappas M, Permezel M, Rice G E. Leptin and adiponectin stimulate the release of proinflammatory cytokines and prostaglandins from human placenta and maternal adipose tissue via nuclear factor-B, peroxisomal proliferator-activated receptor-and extracellularly regulated kinase $1 / 2$. Endocrinology 2005; 146: 3334-3342.

18. Pladevall M, Williams K, Guyer H et al. The association between leptin and left ventricular hypertrophy: a population-based cross-sectional study. J Hypertens 2006; 7: 1447.

19. Mertens I, Van Gaal L F, Obesity, haemostasis and the fibrinolytic system. Obes Rev 2002; 3: 85-101.

20. Guardiola J J, Fletcher E C, Alhariri H et al. Hypercoagulability in obstructive sleep apnea. Topics in pulmonary medicine. Clin Pulm Med 2001; 4: 238-241.
21. Cheah M H, Kam P C. Obesity: basic science and medical aspects relevant to anaesthetists. Anaesthesia 2005; 10: 1009-1021.

22. Kenchaiah S, Evans J C, Levy D et al. Obesity and the risk of heart failure. N Eng/ J Med 2002 734: 305-313.

23. Shah S, lqbal M, Karam J et al. Oxidative stress, glucose metabolism, and the prevention of type 2 diabetes: pathophysiological insights. Antioxid Redox Signal 2007; 7: 911-929.

24. Grunstein R R, Stenlof K, Hedner L et al. Impact of obesity and obstructive sleep apnea and sleepiness on metabolic and cardiovascular risk factors in the Swedish Obese Subjects (SOS) Study. J Int Obes 1995; 19: 410-418.

25. Spriggs D A, French J M, Murdy J M et al. Snoring increases the risk of stroke and adversely affects prognosis. Q J Med 1992; 83: 555-562.

26. Calle E E, Thun M J. Obesity and cancer. Oncogene 2004: 23: 6365-6378.

27. Jou J, Choi S S, Diehl A M. Mechanisms of disease progression in nonalcoholic fatty liver disease. Semin Liver Dis 2008; 28: 370-379.

28. Stein C J, Colditz G A. The epidemic of obesity. J Clin Endocrinol Metab 2004; 89: 6385.

29. Lagergren J. Body measures in relation to gastroosesophageal reflux. Gut 2007; 526: 741-742.

30. Powell A, Teichtahl A J, Wluka A E et al. Obesity: a preventable risk factor for large joint osteoarthritis which may act through biomechanical factors. Br J Sports Med 2005; 39: 4-5.

31. Norman R J, Clark A M. Obesity and reproductive disorders: a review. Reprod Fertil Dev 1998; 10: 55-63

32. Esposito K, Giugliano D. Obesity, the metabolic syndrome, and sexual dysfunction. Int J Impot Res 2005; 17: 391-398.

33. Heling I, Sgan-Cohen, Itzhaki M et al. Dental complications following gastric restrictive bariatric surgery. Obes Surg 2006; 16: 1131-1134.

34. Al-Zahrani M S, Bissada N F, Borawsk E A. Obesity and periodontal disease in young, middle-aged, and older adults. J Periodonto/ 2003; 74: 610-615.

35. www.diaco.co.uk. Accessed 13 March 2009.

36. Beevers G, Lip G, O'Brien E. ABC of hypertension. Blood pressure measurement, Part I, Sphygmomanometry: Factors common to all techniques. BMJ 2001; 322: 981-985.

37. Constantino T G, Parikh A K, Satz W A et al. Ultrasonography-guided peripheral intravenous access versus traditional approaches in patients with difficult intravenous access. Ann Emerg Med 2005; 46: 456-461.

38. Adams J P, Murphy P G. Obesity in anaesthesia and intensive care. Br J Anaesth 2000; 85: 91-108.

39. Magliocca K R, Helman J I. Obstructive sleep apnea. diagnosis, medical management and dental implications. J Am Dent Assoc 2005; 136: 1121-1129.

40. Risk Assessment and Process Planning for Bariatric Patient Handling Pathways. Health and Safety Executive 2007.

41. Kantovitz K R, Pascon F M, Rontani R M et al. Obesity and dental caries - a systematic review. Oral Health Prev Dent 2006; 4: 137-144. 